ORIGINAL ARTICLE

\title{
Derivation of the children's head injury algorithm for the prediction of important clinical events decision rule for head injury in children
}

\author{
J Dunning, J Patrick Daly, J-P Lomas, F Lecky, J Batchelor, K Mackway-Jones, on behalf of the \\ children's head injury algorithm for the prediction of important clinical events (CHALICE) study \\ group
}

See end of article for authors' affiliations

Correspondence to: J Dunning, Emergency Medicine Research Group, Emergency Department, Manchester Royal Infirmary, Oxford Road, Manchester M13 9WL, UK; joeldunning@doctors. org.uk

Accepted 12 June 2006

\begin{abstract}
Background: A quarter of all patients presenting to emergency departments are children. Although there are several large, well-conducted studies on adults enabling accurate selection of patients with head injury at high risk for computed tomography scanning, no such study has derived a rule for children.

Aim: To conduct a prospective multicentre diagnostic cohort study to provide a rule for selection of highrisk children with head injury for computed tomography scanning.

Design: All children presenting to the emergency departments of 10 hospitals in the northwest of England with any severity of head injury were recruited. A tailor-made proforma was used to collect data on around 40 clinical variables for each child. These variables were defined from a literature review, and a pilot study was conducted before the children's head injury algorithm for the prediction of important clinical events (CHALICE) study. All children who had a clinically significant head injury (death, need for neurosurgical intervention or abnormality on a computed tomography scan) were identified. Recursive partitioning was used to create a highly sensitive rule for the prediction of significant intracranial pathology.

Results: 22772 children were recruited over $2 \frac{1}{2}$ years. $65 \%$ of these were boys and $56 \%$ were $<5$ years old. 281 children showed an abnormality on the computed tomography scan, 137 had a neurosurgical operation and 15 died. The CHALICE rule was derived with a sensitivity of $98 \%$ (95\% confidence interval (Cl) $96 \%$ to $100 \%$ ) and a specificity of $87 \%(95 \% \mathrm{Cl} 86 \%$ to $87 \%)$ for the prediction of clinically significant head injury, and requires a computed tomography scan rate of $14 \%$.

Conclusion: A highly sensitive clinical decision rule is derived for the identification of children who should undergo computed tomography scanning after head injury. This rule has the potential to improve and standardise the care of children presenting with head injuries. Validation of this rule in new cohorts of patients should now be undertaken.
\end{abstract}

injury, which would identify children at high risk so as to undergo computed tomography scanning and allow the remaining patients to be discharged with no investigation.

\section{METHODS}

\section{Study setting and population}

A prospective diagnostic cohort study was undertaken from February 2000 to August 2002, which aimed to recruit all patients <16 years presenting with head injury, who attended the emergency departments of 10 hospitals in the northwest of England. Three of these hospitals were children's hospitals, three were teaching hospitals and four were district general hospitals.

\section{Inclusion criteria}

Clinical symptoms and signs in young children can be unreliable, and therefore there is no universally agreed category of "trivial" head injury for which there is no risk of a major intracranial complication. Our inclusion criteria for this study were therefore as wide as possible. Any patient with a history or signs of injury to the head was eligible for inclusion into the study. In particular, loss of consciousness (LOC) or amnesia was not a requirement for entry. We also

Abbreviations: CHALICE, children's head injury algorithm for the prediction of important clinical events; LOC, loss of consciousness; RCS, Royal College of Surgeons; SXR, skull radiograph
Our aim was to derive a sensitive clinical decision rule for the management of children presenting with an acute head 
wanted to reflect the whole population with head injuries attending emergency departments and thus did not exclude patients with a head injury that may have been defined as "moderate or severe". The only exclusion criterion was refusal to consent to entry into the study.

\section{Standardised patient assessment}

A specifically designed proforma was created for data collection. This proforma collected data on around 40 clinical variables pertaining to head injury, including variables on the mechanism of injury, symptoms, signs and management of the patient. Every doctor who participated in the study was given a 1-h training session on the study and the use of this proforma for data collection. Primary assessment of all patients who were eligible for our study was conducted using this proforma. This proforma also functioned as the patient's clinical record on admission.

Response rates and quality of completion were monitored in all centres on a monthly basis to ensure high compliance. All doctors were asked to follow the 1999 Royal College of Surgeons (RCS) guidelines for the management of head injuries ${ }^{17}$ and the guidelines were printed clearly on the front of every proforma.

\section{Outcome measures}

The primary outcome measure was a composite comprising death as a result of head injury, requirement for neurosurgical intervention or marked abnormalities on the computed tomography scan (together referred to as "clinically significant intracranial injury"). In contrast with studies on adults where consensus has been reached as to the nature of what constitutes a clinically important brain injury, no consensus has been reached regarding children in studies either in the

Table 1 Demographics of the children's head injury algorithm for the prediction of important clinical events study $(n=22772)$

\begin{tabular}{|c|c|}
\hline Clinical variable & $\begin{array}{l}\text { Patients } \\
\text { n (\%) }\end{array}$ \\
\hline \multicolumn{2}{|l|}{ Age $^{*}$} \\
\hline $0-6$ months & $852(3.7)$ \\
\hline 6 months-1 year & $1600(7.0)$ \\
\hline $1-2$ years & $3777(16.6)$ \\
\hline $2-5$ years & $6492(28.5)$ \\
\hline $5-11$ years & $6577(28.9)$ \\
\hline $11-16$ years & 3340 (14.7) \\
\hline \multicolumn{2}{|l|}{ Sex† } \\
\hline Male:female & 14767 (64.8):7941 (34.9) \\
\hline \multicolumn{2}{|l|}{ LOC } \\
\hline Any LOC & $1185(5.2)$ \\
\hline$L O C>1 \mathrm{~min}$ & $524(2.3)$ \\
\hline $\mathrm{LOC}>5 \mathrm{~min}$ & $213(0.9)$ \\
\hline \multicolumn{2}{|l|}{ Amnesia } \\
\hline Any amnesia & $720(3.2)$ \\
\hline Amnesia $1 \mathrm{~min}$ & $488(2.1)$ \\
\hline Amnesia $>5 \mathrm{~min}$ & $288(1.3)$ \\
\hline \multicolumn{2}{|l|}{ Vomiting } \\
\hline$\geqslant 1$ & $2498(11)$ \\
\hline$\geqslant 2$ & $1418(6.2)$ \\
\hline$\geqslant 3$ & $857(3.8)$ \\
\hline \multicolumn{2}{|l|}{ Headache } \\
\hline Any headache & $4783(21)$ \\
\hline Severe headache & $95(0.4)$ \\
\hline \multicolumn{2}{|l|}{ GCS } \\
\hline 15 & $21996(96.6)$ \\
\hline 14 & $229(1.0)$ \\
\hline 13 & $73(0.3)$ \\
\hline$<13$ & $193(0.9)$ \\
\hline Doctor unable to determine GCS & $281(1.2)$ \\
\hline \multicolumn{2}{|c|}{$\begin{array}{l}\text { GCS, Glasgow Coma Score; LOC, loss of consciousness. } \\
{ }^{*} 134(0.6 \%) \text { patients had undocumented category. } \\
\dagger 64(0.3 \%) \text { patients had undocumented category. }\end{array}$} \\
\hline
\end{tabular}

US or in the UK. ${ }^{916}$ We defined the computed tomography outcome measure as any new, acute, traumatic intracranial pathology as reported by the consultant radiologist, including intracranial haematomas of any size, cerebral contusion, diffuse cerebral oedema and depressed skull fractures. Simple or non-depressed skull fractures alone were not considered to be significant. Secondary outcome measures were the presence of a skull fracture or admission to hospital.

All patients who were documented as having had a skull radiograph, admission to hospital, computed tomography scanning or neurosurgery were followed up. Radiology departments across the 10 hospitals in the study and also from two further tertiary neurosurgical referral centres in the northwest of England (The Walton Centre, Liverpool, and Pendlebury Hospital, Manchester) collated data separately on every child who had a skull radiograph or computed tomography scan of the brain. In addition, hospitals prospectively collated data on patients who were admitted, underwent neurosurgery, stay in the intensive care unit or neurorehabilitation from these 12 centres. These data were then cross-checked with those in the database of the children's head injury alorithm for the prediction of important clinical events (CHALICE). The Office of National Statistics provided us with the details of children in the UK who died, in whom head injury was any part of the cause of death.

\section{Ethical approval}

Multicentre ethical approval was obtained for this study. Verbal consent to participate in this study was obtained from all patients or guardians before entry into the study. The doctor who obtained consent indicated acceptance on the proforma.

\section{Statistical analysis}

Sample size that would allow us to derive, with an $80 \%$ power, a clinical decision rule with 100\% sensitivity and a lower confidence limit $>95 \%$ was initially calculated. This required 75 patients with a positive outcome; thus, at an incidence of $1 \%$ for clinically significant brain injury, we required 7500 patients and a l-year study. At interim

Table 2 Patient management and outcomes ( $n=22$ 772)

\begin{tabular}{ll}
\hline & Patients \\
\hline SXR taken & $5318(23.4)$ \\
Skull fracture on SXR & $259(1.1)$ \\
Skull fracture on SXR or CT & $421(1.9)$ \\
Linear fracture & $233(1.0)$ \\
Complex fracture & $36(0.2)$ \\
Depressed fracture & $80(0.4)$ \\
Basilar fracture & $67(0.3)$ \\
Intracranial air & $57(0.3)$ \\
CT scanning carried out & $766(3.3)$ \\
Abnormality on CT scan & $281(1.2)$ \\
Epidural haematoma & $91(0.4)$ \\
Subdural haematoma & $54(0.2)$ \\
Cerebral contusion & $83(0.4)$ \\
Subarachnoid haemorrhage & $28(0.1)$ \\
Cerebral oedema & $58(0.3)$ \\
Admission & $1461(6.4)$ \\
Length of stay* & $3.5,1(1-95)$ days \\
Length of stay with normal CT* & $1.8,1(1-33)$ days \\
Length of stay with abnormal CT* & $10.7,6(1-95)$ days \\
Neurosurgical operation & $137(0.6)$ \\
Intubation or ICP monitoring & $157(0.7)$ \\
Mortality & $15(0.1)$ \\
\hline
\end{tabular}

Values are $\mathrm{n}(\%)$ unless otherwise mentioned. $\mathrm{CT}$, computed tomography; ICP, intracranial pressure; SXR, skull radiograph.

*Values are mean, median (range). 
analysis, patients who were difficult to predict were identified and thus the study was extended to keep the lower confidence interval $>95 \%$.

Univariate analysis was carried out using Fisher's exact test for binomial categorical data or the $\chi^{2}$ test for unranked categorical data. Non-parametric rank data or continuous data were analysed using the Mann-Whitney U test, and unpaired Student's t test was used for continuous data with a normal distribution. Interobserver agreement for each variable was calculated using the $\kappa$ coefficient-that is, the proportion of potential agreement beyond chance-along with its $95 \%$ confidence interval (CI) in a subset of patients. In this subset from two centres, patients were seen twice by clinicians in the study and their results were compared. A weighted $\kappa$ was calculated for rank variables. ${ }^{18} 19$

Variables that were both reproducible $(\kappa>0.6)$ and associated with the outcome measure $(p<0.1)$ were assessed by multivariate analysis using recursive partitioning. The primary objective of the multivariate analysis was to find the best combinations of predictor variables that were highly sensitive for detecting the presence of a clinically significant intracranial injury, while achieving the maximum possible specificity.

Our experience and that of other groups ${ }^{920}$ suggest that recursive partitioning may be more suitable than logistic regression when the objective is to correctly classify one outcome at the expense of the other-that is, when high sensitivity is more important than specificity.

Univariate analysis was carried out using SPSS V.11.5 and recursive partitioning using CART V.4.0 (Salford Systems, San Diego, California, USA), using the GINI splitting rule with a 3 to 1 weighting against misclassification of positive intracranial pathology.

\section{RESULTS}

In all, 22772 patients were enrolled into the study, of whom 12471 were from children's hospitals, 3241 from teaching hospitals and 7060 from district general hospitals. In all, 65\% of these were boys and $56 \%$ were $<5$ years old (table 1 ). The mean age was 5.7 years. Out of 744 computed tomography scans, scans of $281(1.2 \%)$ patients showed an abnormality ( $3.2 \%$ of the cohort, of which $37.7 \%$ showed abnormality). In all, $1461(6.4 \%)$ children were admitted, $137(0.6 \%)$ had a neurosurgical operation and 15 children died.

In all 5318 skull radiographs (SXRs) were taken, from which 259 skull fractures were diagnosed after radiologist reporting (table 2). However, 44 (17\%) fractures were missed by emergency physicians and 59 ( $1 \%$ of normal radiographs) fractures diagnosed by emergency physicians were normal, giving a correlation between radiologists and emergency physicians of $\kappa=0.80$. Ninety eight patients with abnormality on computed tomography scan also had an SXR. SXRs reported by emergency physicians had a sensitivity of $77 \%$ (95\% CI $67 \%$ to $85 \%$, 75 fractures in 98 patients) for the prediction of positive pathology on computed tomography scanning.

Doctors were asked to use the 1999 RCS guidelines for the management of head injuries. These guidelines recommend all patients at high risk to be admitted, with computed tomography scanning for those with the highest risk. This protocol resulted in 1461 admissions, but 10 patients were sent home before returning and proving to have an abnormality on the computed tomography scan. Also, another two patients were admitted for a brief time and sent home without being scanned, only to return with intracranial pathology shown on the subsequent computed tomography scan. Of these 12 patients, seven required neurosurgery. Two patients with intracranial pathology who were discharged presented to a different hospital on their second attendance. Of patients who were admitted for observation without immediate computed tomography scanning, 27 patients deteriorated on the ward and 24 of these patients required neurosurgery. Table 2 gives the full details of radiographic and admission demographics.

Univariate analysis was carried out using the primary outcome measure. Table 3 gives the univariate analysis of those variables selected in the final model. The full analysis of the association between all clinical variables and primary outcome is available online at http://www.archdischild.com/ supplemental. All variables that showed a univariate relationship with $\mathrm{p}<0.1$ were entered into multivariate analysis.

Table 3 Association between significant clinical variables and primary outcome

\begin{tabular}{|c|c|c|c|c|c|}
\hline Finding & $\begin{array}{l}\text { Total }(\%) \\
(n=22772)\end{array}$ & $\begin{array}{l}\text { Negative for clinically } \\
\text { significant intracranial } \\
\text { pathology } \\
(n=22491)\end{array}$ & $\begin{array}{l}\text { Positive for clinically } \\
\text { significant intracranial } \\
\text { pathology } \\
(n=281)\end{array}$ & p Value & $\begin{array}{l}\text { Positive predictive } \\
\text { value }\end{array}$ \\
\hline \multicolumn{6}{|l|}{ History } \\
\hline $\mathrm{LOC}>5 \mathrm{~min}$ & $213(0.9)$ & $118(0.5)$ & $95(34)$ & $<0.001$ & 0.45 \\
\hline Amnesia $>5 \mathrm{~min}$ & 288 (1.3) & $226(1.0)$ & $62(22)$ & $<0.001$ & 0.22 \\
\hline Drowsiness & 949 (4.2) & $889(4.0)$ & $60(21)$ & $<0.001$ & 0.063 \\
\hline Vomiting $\geqslant 3$ times & 857 (3.8) & $801(3.6)$ & $56(20)$ & $<0.001$ & 0.065 \\
\hline Suspicion of NAl & $61(0.3)$ & $41(0.2)$ & $20(7.1)$ & $<0.001$ & 0.33 \\
\hline $\begin{array}{l}\text { Seizure after head injury (in patients } \\
\text { without epilepsy) }\end{array}$ & $96(0.4)$ & $68(0.3)$ & $28(10)$ & $<0.001$ & 0.29 \\
\hline \multicolumn{6}{|l|}{ Examination } \\
\hline GCS $<14$ & $266(1.2)$ & $137(0.6)$ & $129(46)$ & $<0.001$ & 0.48 \\
\hline GCS $<15$ if age $<1$ year & $79(0.3)$ & $71(0.3)$ & $8(2.8)$ & $<0.001$ & 0.10 \\
\hline $\begin{array}{l}\text { Penetrating or depressed skull injury } \\
\text { suspected or tense fontanelle }\end{array}$ & $104(0.5)$ & $58(0.3)$ & $46(16)$ & $<0.001$ & 0.44 \\
\hline Base of skull fracture suspected & $536(2.4)$ & $451(2.0)$ & $85(30)$ & $<0.001$ & 0.16 \\
\hline Positive focal neurology & $150(0.7)$ & $96(0.4)$ & $54(19)$ & $<0.001$ & 0.36 \\
\hline $\begin{array}{l}\text { Presence of bruise/swelling or laceration } \\
>5 \mathrm{~cm} \text { in children aged }<1 \text { year }\end{array}$ & $52(0.2)$ & $46(0.2)$ & $6(2.1)$ & $<0.001$ & 0.12 \\
\hline \multicolumn{6}{|l|}{ Mechanism } \\
\hline High-speed RTA & $204(0.9)$ & $117(0.5)$ & $87(31)$ & $<0.001$ & 0.43 \\
\hline Fall $>3 \mathrm{~m}$ & $129(0.6)$ & $103(0.5)$ & $26(9.3)$ & $<0.001$ & 0.20 \\
\hline High-speed injury from projectile or object & $456(2.0)$ & $438(1.9)$ & $18(6.4)$ & $<0.001$ & 0.039 \\
\hline
\end{tabular}


The common clinical variables with unknown reproducibility were analysed in a subset of the CHALICE study. In all, 412 patients had their clinical condition assessed in this way. Good agreement was found for LOC $(\kappa=1,95 \%$ CI 0.84 to 1$)$, amnesia $(\kappa=0.93,95 \%$ CI 0.79 to 1$)$ and vomiting ( $\kappa=0.94$, $95 \%$ CI 0.81 to 1 ), but headache showed poor correlation $(\kappa=0.39,95 \%$ CI 0.25 to 0.54$)$ and was rejected from multivariate modelling owing to its poor predictive ability.

Recursive partitioning analysis produced a highly sensitive model, (see box). As shown in the clinical utility analysis (table 4), this model has an overall sensitivity of 98\% (95\% CI $96 \%$ to $100 \%$ ) and an overall specificity of $87 \%$ (95\% CI $86 \%$ to $87 \%$ ). Our model misses only four patients, of whom two had depressed skull fractures that the physician did not suspect on examination, but on reattendance subsequent physicians documented that the depressions were easily palpable. The third patient had an unwitnessed fall against a wall. Initial examination found no high-risk variables and the patient was discharged, but the patient returned $2 \mathrm{~h}$ later, vomiting. He was admitted overnight, and the scan the next morning showed an epidural haematoma that required neurosurgery. The fourth patient had a fall into a stream from a swing, and had brief amnesia and a moderate headache. He was discharged but returned 11 days later with a persisting headache. A linear skull fracture and a small subdural and epidural haematoma were found that required no treatment.

\section{DISCUSSION}

We have successfully derived a highly sensitive clinical decision rule for the prediction of clinically significant intracranial pathology in children according to strict methodological standards, in the world's largest prospective cohort of children with head injuries. This rule, if validated, will enable clinicians to request computed tomography scans for their patients on the basis of strong evidence in children.

If our rule is subsequently validated, we believe that patients regarded as high risk should undergo computed tomography scanning to look for intracranial pathology, whereas those with a normal scan might be regarded as low risk. Children who are regarded as low risk by a validated rule should be carefully counselled so that they understand the high-risk symptoms for which they should return. Although the CHALICE rule will increase the rate of computed tomography scanning, we envisage that the admission rate could be markedly reduced and thus the cost implications of our rule could be neutral. This remains to be shown in further studies.

Any decision rule that is to be of value to clinicians seeing undifferentiated children with head injury must be applicable to all such children. At study design stage it was important to take a pragmatic approach to this requirement, as it was clear that the rate of significant events was low and that it would be unethical to expose large numbers of children to unnecessary major radiation exposure. A balance needed to be struck between inclusion bias (selecting only children who already fulfilled some existing rule, which indicated that they should undergo computed tomography scanning) and the ethical limits that would be placed on the study. Thus, a composite end point was agreed and ethically approved. This involved the identification of all children who died, had neurosurgical intervention or had abnormalities on a computed tomography scan. This composite end point was reinforced with a prospective, thorough follow-up strategy, which was designed to ensure that no children who died as a result of their head injury or who had late neurosurgical intervention were missed. Although this approach can be criticised because some children with abnormalities on the computed tomography scan may not have been identified as
The children's head injury algorithm for the prediction of important clinical events rule

A computed tomography scan is required if any of the following criteria are present.

- History

- Witnessed loss of consciousness of $>5$ min duration

- History of amnesia (either antegrade or retrograde) of $>5$ min duration

- Abnormal drowsiness (defined as drowsiness in excess of that expected by the examining doctor)

$-\geqslant 3$ vomits after head injury (a vomit is defined as a single discrete episode of vomiting)

- Suspicion of non-accidental injury (NAI, defined as any suspicion of NAl by the examining doctor)

- Seizure after head injury in a patient who has no history of epilepsy

- Examination

- Glasgow Coma Score (GCS) $<14$, or GCS $<15$ if $<1$ year old

- Suspicion of penetrating or depressed skull injury or tense fontanelle

- Signs of a basal skull fracture (defined as evidence of blood or cerebrospinal fluid from ear or nose, panda eyes, Battles sign, haemotympanum, facial crepitus or serious facial injury)

- Positive focal neurology (defined as any focal neurology, including motor, sensory, coordination or reflex abnormality)

- Presence of bruise, swelling or laceration $>5 \mathrm{~cm}$ if $<1$ year old

- Mechanism

- High-speed road traffic accident either as pedestrian, cyclist or occupant (defined as accident with speed $>40 \mathrm{~m} / \mathrm{h}$ )

- Fall of $>3 \mathrm{~m}$ in height

- High-speed injury from a projectile or an object

If none of the above variables are present, the patient is at low risk of intracranial pathology.

they did not undergo such scanning, it has considerable strength in that children with both immediate or late significant events are included. Thus, it can be assumed that any undiagnosed abnormalities on the computed tomography scan were clinically non-significant. We believe that this method is superior to the alternative one of telephoning each patient 2 weeks after admission, and previous studies have been criticised for their inability to contact all patients for follow-up. ${ }^{91}$

We do not believe that there is considerable circularity between the clinical care drivers during the study and the findings as stated in the CHALICE rule. In particular, the recommendations of the $\mathrm{RCS}^{17}$ differ from those of the CHALICE in that a major indication for computed tomography in a district general hospital as per the RCS guidance is fracture on the SXR. CHALICE has looked critically at both the indications for SXR and the computed tomography scan in detail, and distilled from a long list (table A available at http://www.archdischild.com/supplemental) those that truly 


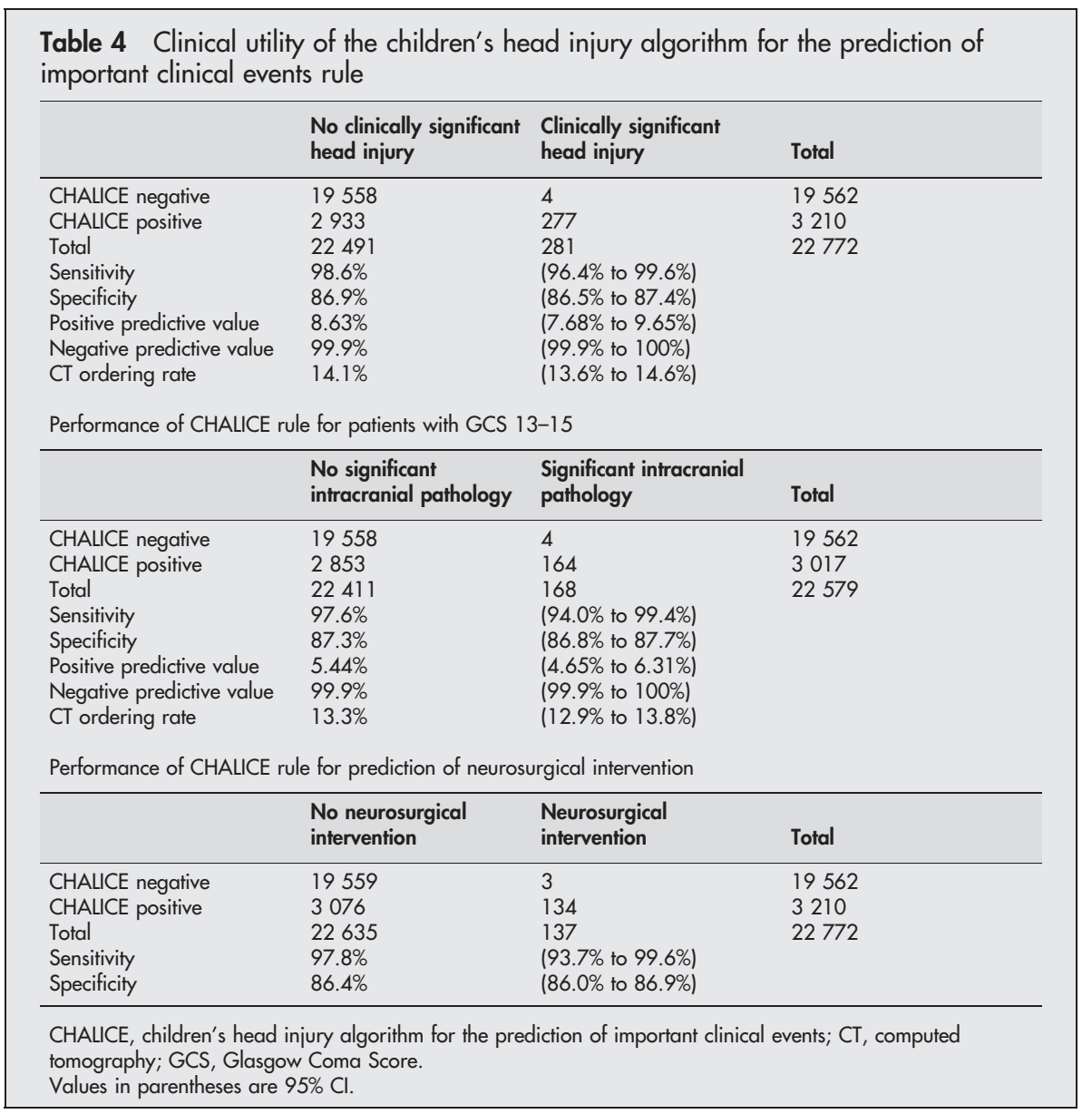

indicate the likelihood of clinically significant intracranial injury (the composite outcome). It is not surprising that some of the CHALICE rules support previous expert opinion. Perhaps it would be more surprising if it did not.

Our study has other limitations. Clinicians were not always blinded to the outcome of the computed tomography scan before completing the proforma. Although clinicians completed most proformas on the first clinical examination, they were reminded at a later date if they did not do this. Our proforma was also the clinical record sheet and, thus, compliance was generally high. However, we do not have data on the number of missed patients that could have been eligible. Finally, our study is only a derivation study and it should now be prospectively validated, with its reproducibility, acceptability, usability and economic effect evaluated across multiple sites.

Few studies have successfully derived a clinical decision rule applicable to all children from a large cohort of patients. Palchak et $a^{23}$ in 2003 derived a rule on examining 2043 patients from a single hospital, aged $<18$ years, who had had head trauma and showed positive findings on history or clinical examination such as LOC, amnesia, vomiting or headache. Of nine predictive variables assessed, abnormal mental status, clinical signs of skull fracture, history of vomiting, scalp haematoma (in children aged $\leqslant 2$ years) or headache identified 96 of 98 patients with positive intracranial pathology on computed tomography scanning $(98 \%$ sensitivity, $95 \%$ CI $93 \%$ to $100 \%$ ).

Greenes and Schutzman ${ }^{23}$ conducted a prospective study on 608 patients aged $<2$ years in a single hospital. ${ }^{23}$ Their results support our finding that children with suspected non-accidental injury, history of lethargy or a major scalp haematoma had an increased risk of significant intracranial injury. In addition, they found that LOC, seizures or vomiting alone was not adequate to predict intracranial injury, and that the absence of clinical symptoms or signs did not fully exclude the possibility of uncovering positive pathology. Together with a systematic review by the American Academy of Pediatrics and expert consensus, these authors formalised this study by producing guidelines for head injuries in children $<2$ years old. ${ }^{24}$ They allocated patients into four risk groups, with computed tomography scanning recommended in the highest risk group of children who vomited $>3$ times or had an LOC, a history of lethargy, a high-risk mechanism or considerable bruising. Although these guidelines agree with many of our recommendations, including the suggestion that patients are safe for discharge after a negative finding on a computed tomography scan, like ours, their guidelines have not yet been validated in other hospitals.

Haydel and Shembekar ${ }^{25}$ in 2003 assessed the New Orleans criteria $^{13}$ in children aged $>5$ years. They assessed 175 children with GCS 15 from a single institution and concluded that the 14 positive computed tomography scans that they found could be identified by their rule, which was derived from and validated in scans of adults.

The National Institute of Clinical Excellence, UK, systematically reviewed all studies on head injury up to 2002. They concluded that no studies on childhood head injury could be used to construct a robust rule, and advocated extrapolating the Canadian CT head rule for children. We assessed the performance of this rule in children, ${ }^{26}$ extending our previous work to the full database. We found that the sensitivity was $94 \%$ (95\% CI $91 \%$ to $97 \%$ ) and the specificity was $89 \%$ (95\% CI $89 \%$ to $90 \%$ ), with a computed tomography ordering rate 
of $12 \%$. Sixteen patients would have been missed if this rule had been strictly applied to our database. Thus, we conclude that the CHALICE rule is safer than extrapolating an adult head injury guideline to children without a considerably increased computed tomography ordering rate. We also found that the RCS guidelines were being poorly applied to children, with half the radiographs, admissions and computed tomography scans recommended by the RCS guidelines not being carried out. ${ }^{26}$

Many of the variables identified as significant in our study have also been identified in a meta-analysis of clinical variables identified from 16 papers in the paediatric literature. ${ }^{27}$ Focal neurology, seizures, LOC and abnormal GCS were all major predictors, but headache was found not to considerably predict significant intracranial pathology.

Although computed tomography scanning is a safe procedure for those who are able to comply with the investigation, young children may require sedation, which is not without complications. ${ }^{28}$ Occasionally, the risk of the investigation should be balanced with the possibility of delayed diagnosis with observation alone in children who have been identified as high risk by our rule.

Finally, we do not support the continued use of SXR for children with acute head injury, except for highly selected patients who may have had non-accidental injury. Although many studies have found that the evidence of a fracture on SXR markedly increases the incidence of intracranial pathology, ${ }^{29-31}$ we agree with other studies that the SXR has a poor sensitivity for identifying patients with intracranial pathology, that fractures are identified on only a small number of radiographs and that fractures are easily missed by those interpreting the radiographs. ${ }^{32}$ We thus advocate that a clear decision rule (such as the CHALICE rule) that uses clinical variables alone and that identifies children at high risk of significant intracranial injury for computed tomography scanning is the optimal rule for the management of head injuries in children.

\section{CONCLUSION}

The CHALICE rule, derived from 22772 children attending the emergency departments of 10 hospitals in the UK, may provide a comprehensive clinical decision rule for the management of head injuries in children that identifies patients at risk of significant intracranial pathology. Validation studies are now needed.

\section{ACKNOWLEDGEMENTS}

We thank the following clinicians for assistance: Rosemary Morton, Manchester Royal Infirmary; David Lloyd, Helen Carty and Barbara Phillips, Alder Hey Hospital; Patricia Brennan, Sheffield Children's Hospital; Marion Waters, Countess of Chester Hospital, Chester; Steven Southworth, Stepping Hill Hospital; S Kumar, Royal Oldham Hospital; Kasem Ali, Bury General Hospital; Brendan Ryan, Wythenshawe Hospital; Lorcan Duane, Booth Hall Children's Hospital. We also thank Steve Roberts, Medical Statistician, Manchester Royal Infirmary.

\section{Authors' affiliations}

J Dunning, J-P Lomas, J Batchelor, K Mackway-Jones, Emergency

Medicine Research Group (EMERGE), Emergency Department,

Manchester Royal Infirmary, Manchester, UK

J P Daly, Manchester Computing, University of Manchester, Manchester F Lecky, Emergency Department, Hope Hospital, Manchester

Funding: This study was funded by the Enid Linder Foundation Research Fellowship from the Royal College of Surgeons of England, The Child Brain Injury Trust and The Dickinson Trust. None of these funding bodies had any role in the conduct of the study or in the preparation of the manuscript.

Competing interests: None.

\section{What is already known on this topic}

- 1 in 500 children with a minor head injury will have serious intracranial complications.

- Clinical guidelines extrapolated from adult guidelines and expert consensus are currently available to identify these patients in the emergency department.

\section{What this study adds}

- The CHALICE rule identifies children at high risk of serious intracranial complications following a head injury.

- The CHALICE rule is the first head injury decision rule derived entirely from prospective multicentre data from head injuries in children. The CHALICE database is the world's largest prospective cohort study in childhood head injuries with 22772 children studied from 10 centres.

This paper conforms to the STARD guidelines for reporting of diagnostic cohort studies.

Contributors: JD was the lead researcher, and led the study and prepared the manuscript. KM-J conceived the project, obtained funding, supervised the research, and oversaw and supervised its conduct. JPD created the proforma and supervised data collation. J-PL carried out the analysis for interobserver agreement. FL and JB organised the multicentre participation and supervised its conduct. All authors had access to all study data and participated in manuscript preparation and checking.

\section{REFERENCES}

1 Teasdale GM. Head injury. J Neurol Neurosurg Psychiatry 1995;58:526-39.

2 MacMillan R, Jennett B. Epidemiology of head injury. BMJ 1981;282:101-7.

3 Brookes M, MacMillan R, Cully S, et al. Head injuries in accident and emergency departments. How different are children from adults? J Epidemiol Community Health 1990;44:147-51.

4 Kraus JF, Fife D, Cox P, et al. Incidence, severity and external causes of pediatric brain injury. Am J Dis Child 1986;140:687-93.

5 Kraus JF, Rock A, Hemyari P. Brian injuries among infants, children adolescents, and young adults. Am J Dis Child 1990;144:684-91.

6 Division of Injury Control CFDC. Childhood injuries in the United States. Am J Dis Child 1990;144:627-46.

7 Swann IJ, MacMillan R, Strong I. Head injuries at an inner city accident and emergency department. Injury 1981;12:274-8.

8 Swann IJ, Teasdale GM. Current concepts in the management of patients with so-called 'minor' or 'mild' head injury. Trauma 1999; 1:143-5.

9 Stiell IG, Wells GA, Vandemheen K, et al. The Canadian CT head rule for patients with minor head injury. Lancet 2001;357:1391-6.

10 Borczuk P. Predictors of intracranial injury in patients with mild head trauma. Ann Emerg Med 1995;25:731-6.

11 Servadei F, Teasdale G, Merry G. Defining acute mild head injury in adults: a proposal based on prognostic factors, diagnosis, and management. $J$ Neurotrauma 2001;18:657-64.

12 Miller EC, Holmes JF, Derlet RW. Utilizing clinical factors to reduce head CT scan ordering for minor head trauma patients. J Emerg Med 1997;15:453-7.

13 Haydel MJ, Preston CA, Mills TJ, et al. Indications for computed tomography in patients with minor head injury. N Engl J Med 2000;343:100-5.

14 Stiell IG, Wells GA. Methodological standards for the development of clinical decision rules in emergency medicine. Ann Emerg Med 1993:33:437-47.

14a American Academy of Pediatrics. The management of minor closed head injury in children. Pediatrics 1999;104:1407-15.

15 Homer CJ, Kleinman L. Technical report: minor head injury in children. Pediatrics 1999; 104:e78.

16 National Collaborating Centre for Acute Care on Behalf of the National Institute of Clinical Excellence. Head injury: assessment, investigation and early management of head injury in children and adults. www.nice.org/ cat.asp?c $=20087$ (accessed 14 Jul 2003).

17 Royal College Of Surgeons. Report of the Working Party on the management of patients with head injury. London: RCS Eng, 1999.

18 Cohen J. A coefficient of agreement for nominal scales. Educ Psychol Measure, 1960:37-46.

19 Cohen J. Weighted kappa: nominal scale agreement with provision for scaled disagreement or partial credit. Psychol Bull, 1968;70:213-20. 
20 Mower WR, Hoffman JR, Herbert M, et al. Developing a clinical decision instrument to rule out intracranial injuries in patients with minor head trauma: methodology of the NEXUS II investigation. Ann Emerg Med 2002;40:505-14.

21 Maharai I. The Canadian CT head rule. Lancet 2001;358:1013-14.

22 Palchak MJ, Holmes JF, Vance CW, et al. A decision rule for identifying children at low risk for brain injuries after blunt head trauma. Ann Emerg Med 2003;42:492-506.

23 Greenes DS, Schutzman SA. Clinical indicators of intracranial injury in headinjured infants. Pediatrics 1999:104:861-7.

24 Schutzman SA, Barnes P, Duhaime AC, et al. Evaluation and management of children younger than two years old with apparently minor head trauma: proposed guidelines. Pediatrics 2001;107:983-93.

25 Haydel MJ, Shembekar AD. Prediction of intracranial injury in children aged five years and older with loss of consciousness after minor head injury doe to nontrivial mechanisms. Ann Emerg Med 2003;42:507-14.

26 Dunning J, Daly JP, Malhotra R, et al. The implications of NICE guidelines on the management of children presenting with head injury. Arch Dis Child 2004;89:763-7.
27 Dunning J, Batchelor J, Stratford-Smith $\mathrm{P}$, et al. A meta-analysis of variables that predict significant intracranial injury in minor head trauma. Arch Dis Child 2004;89:653-9.

28 Vade A, Sukhani R, Dolenga $M$, et al. Chloral hydrate sedation of children: analysis of children undergoing $C T$ and MR imaging: safety as judged by American Academy of Pediatrics guidelines. Am J Roentgenol 1995; 165:905-9.

29 Teasdale GM, Murray G, Anderson E, et al. Risks of acute traumatic intracranial haematoma in children and adults: implications for managing head injuries. BMJ 1990;300:363-7.

30 Quayle KS, Jaffe DM, Kuppermann N, et al. Diagnostic testing for acute head injury in children: when are head computed tomography and skull radiographs indicated? Pediatrics 1997;99:e11.

31 Shane SA, Fuchs SM. Skull fractures in infants and predictors of associated intracranial injury. Pediatr Emerg Care 1997;13:198-203.

32 Lloyd DA, Carty H, Patterson M, et al. Predictive value of skull radiography for intracranial injury in children with blunt head injury. Lancet 1997;349:821-4.

\section{Clinical Evidence-Call for contributors}

Clinical Evidence is a regularly updated evidence-based journal available worldwide both as a paper version and on the internet. Clinical Evidence needs to recruit a number of new contributors. Contributors are healthcare professionals or epidemiologists with experience in evidence-based medicine and the ability to write in a concise and structured way.

Areas for which we are currently seeking contributors:

- Pregnancy and childbirth

- Endocrine disorders

- Palliative care

- Tropical diseases

We are also looking for contributors for existing topics. For full details on what these topics are please visit www. clinicalevidence.com/ceweb/contribute/index.jsp

However, we are always looking for others, so do not let this list discourage you.

Being a contributor involves:

- Selecting from a validated, screened search (performed by in-house Information Specialists) epidemiologically sound studies for inclusion.

- Documenting your decisions about which studies to include on an inclusion and exclusion form, which we keep on file.

- Writing the text to a highly structured template (about 1500-3000 words), using evidence from the final studies chosen, within 8-10 weeks of receiving the literature search.

- Working with Clinical Evidence editors to ensure that the final text meets epidemiological and style standards.

- Updating the text every 12 months using any new, sound evidence that becomes available. The Clinical Evidence in-house team will conduct the searches for contributors; your task is simply to filter out high quality studies and incorporate them in the existing text.

If you would like to become a contributor for Clinical Evidence or require more information about what this involves please send your contact details and a copy of your CV, clearly stating the clinical area you are interested in, to CECommissioning@bmigroup.com.

\section{Call for peer reviewers}

Clinical Evidence also needs to recruit a number of new peer reviewers specifically with an interest in the clinical areas stated above, and also others related to general practice. Peer reviewers are healthcare professionals or epidemiologists with experience in evidence-based medicine. As a peer reviewer you would be asked for your views on the clinical relevance, validity, and accessibility of specific topics within the journal, and their usefulness to the intended audience (international generalists and healthcare professionals, possibly with limited statistical knowledge). Topics are usually 1500-3000 words in length and we would ask you to review between 2-5 topics per year. The peer review process takes place throughout the year, and out turnaround time for each review is ideally 10-14 days.

If you are interested in becoming a peer reviewer for Clinical Evidence, please complete the peer review questionnaire at www. clinicalevidence.com/ceweb/contribute/peerreviewer.jsp 